\title{
Sinusitis: an improved regime of investigation for the clinical laboratory
}

\author{
R C BRIDGER
}

From the Department of Microbiology, Godfrey Pathology Laboratory, 137 Kilmore Street, Christchurch 1, New Zealand

SUMMARY Clinical material from 200 patients suffering from acute sinusitis was examined cytologically and bacteriologically. Seventy per cent of specimens were collected by aspiration of the middle meatus, $20 \%$ by antral wash, and $10 \%$ by direct swabbing of the antra. A comparison of the results from these differing techniques is made. The bacteriological methods used and the isolates and their significance are discussed, and suggestions are offered for improving the routine demonstration of presumptive pathogens in this disease.

The collection of satisfactory clinical material from infected nasal sinuses is best undertaken by the ear, nose and throat specialist. However, the far greater number of patients under the care of general practitioners generally rely on the clinical laboratory for specimen collection, and here an adequate routine technique is not always available. Swabs of any type are often contaminated by commensal flora, giving results that are at best suspect and at worst frankly misleading (Axelsson and Brorson, 1973). The aspirate method of collection described in this paper appears to produce adequate material during the acute phase of sinusitis, to demonstrate a significant pathogen in most cases, and to be no more than slightly uncomfortable for the patient. It is also simple to operate with a minimum of experience. The bacterial isolation methods employed have produced fewer sterile culture results than are recorded in previously published surveys (Sparrevohn and Buch, 1946; Palva et al., 1962; Lystad et al., 1964; Montgomery Smith and Smith, 1971; Frederick and Braude, 1974), and evidence that a significant number of pathogens may be missed by standard primary isolation methods is offered.

\section{Patients and methods}

PATIENTS

Patients were selected on the following criteria:

(1) A current attack of acute sinusitis with discharging sinus(es). Ideally, where evidence of

Received for publication 10 September 1979 sinus opacity, by either $x$-ray or transillumination, was available, this should be noted.

(2) A past history of sinusitis involving at least one previous acute episode.

(3) No intercurrent infection present, eg a common cold.

(4) No current antibiotic therapy.

Findings from patients not conforming to these criteria were excluded from the results.

All patients undergoing aspiration at the laboratory were seen by request, and the aspirations were undertaken by the author. Materials supplied by ENT specialists were taken by them either by antral wash or by swabs of frank pus, the latter either from sinus puncture or postoperatively.

\section{ASPIRATION APPARATUS}

This comprised a sterile Surflow (Terumo) disposable, winged infusion set from which the needle was removed to leave a flexible, thin, plastic tube with an effective length of about $30 \mathrm{~cm}$. The plastic bevel on the far end of this tube was pushed firmly and rotated on to the hub of a sterile, plastic, disposable $20 \mathrm{ml}$ syringe. The whole assembly is shown in Figure 1.

\section{TECHNIQUE}

The collection of antral pus from the middle meatus in the nasal cavity is undertaken in the following way. The patient is asked to lie supine on a medical couch without the aid of any pillow or other support. The head is rotated sideways to rest on the couch at about $45^{\circ}$ from the horizontal, this inclination being towards the side of the face on which the 


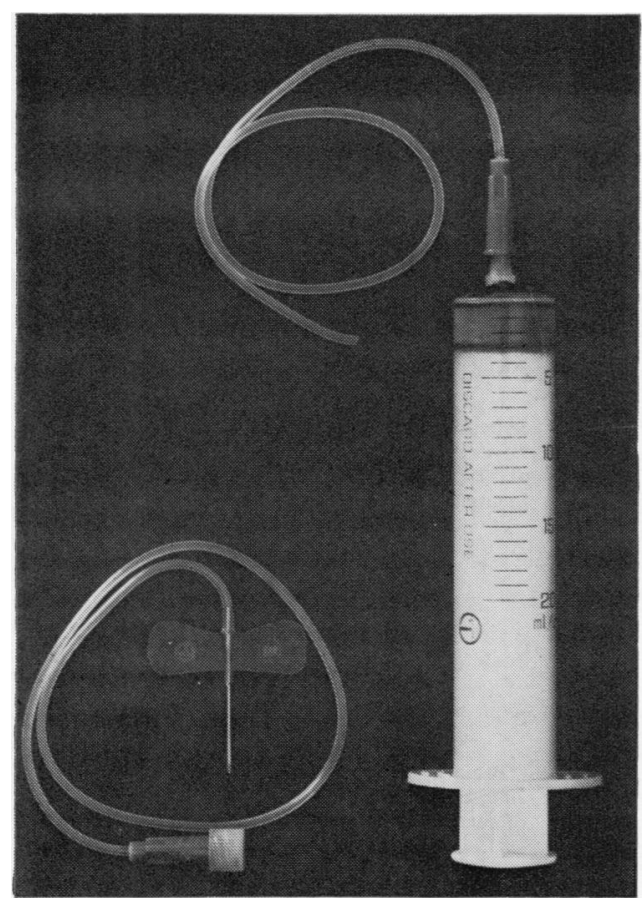

Fig. 1 Left: Complete winged infusion set.

Right: Tube modified and attached to a $20 \mathrm{ml}$ syringe.

patient judges the sinus involvment to be most severe. In the absence of a firm opinion, an arbitrary side is chosen. A wait of up to 5 minutes is made to ensure gravitational drainage from the affected sinus(es) or less if the patient reports passage of exudate down the throat. During the waiting period a simple and reassuring explanation of the technique is given, and the point is emphasised that although the procedure may be slightly uncomfortable and that the eyes may water, no actual pain will be felt.

The open end of the plastic tube is passed gently but firmly up the anterior nares to the posterior nares. By steady pressure and manipulation, the tube, being sufficiently rigid, will take the line of least resistance into the middle meatal area. The distance required to reach this area is about $12 \mathrm{~cm}$ from the outer edge of the external nares in the adult and proportionately less in the child. The syringe, with the plunger extended and held in the other hand, is manipulated to expel air slowly during this passage to exclude the entry of mucus from the nares into the tube. Once the middle meatus is reached, a steady suction is applied. An initial dry tap usually needs only small back and forth movements of the tube to reach exudate. If the syringe fills with air, the plastic bevel is simply rotated off the syringe hub, the syringe plunger is depressed, and the bevel is reattached. Exudate is clearly visible as it descends in a fluid column below the outer edge of the anterior nares. Accidental passage right through to the edge of the soft palate is quickly noted by the patient who generally gags and coughs. The passage of a fresh tube is found to be preferable in these cases to exclude pharyngeal contamination. Given actively draining sinus(es), the whole procedure takes about 1-2 minutes.

Where a totally dry tap was found, the other side often produced an adequate sample and, failing this, a later aspiration, say the next day, was commonly successful in the acute patient.

The exudate was expelled completely from the tube by repeated sharp depressions of the syringe plunger, on to the primary blood agar culture plate and was sufficient to inoculate all media and make two smears on glass slides for staining.

\section{BACTERIOLOGICAL PROCEDURES}

Identification of isolates to species level (Fig. 2) was carried out according to the methods outlined by Cowan and Steel (1974).

\section{ANTIBIOTIC SENSITIVITY TESTS}

Readings of zones of inhibition around discs were measured against the quality control disc template. The antibiotics of most common choice in this condition were used for testing, ie penicillin, ampicillin, erythromycin, tetracycline, and cotrimoxazole.

In view of the problems of penetration into the sinuses of some common antibiotics (Lundberg et al., 1968; Editorial, Lancet, 1974; Agbim, 1975; Eneroth et al., 1975) isolates were reported as either 'sensitive' or 'resistant' to specific antibiotics.

Since only two species of anaerobes, of predictable antibiotic response, were isolated, no sensitivity tests were carried out on these strains. Routine sensitivity of Haemophilus influenzae strains to antibiotics was not undertaken but, in retrospect, a procedure to demonstrate $\beta$-lactamase producers could have been incorporated into the regime to possible clinical advantage (Nelson, 1974).

\section{Results}

The results are shown in Tables 1-3.

STAINED FILMS OF EXUDATES

In the Gram-stained film, 96 showed no conventional organisms on search but pleomorphic, Gram-negative bodies were present in approximately 
Fig. 2 Primary methods of bacterial isolation from exudates.

(Middle meatal aspirate, washings or direct pus)

\begin{tabular}{|l}
$\begin{array}{l}\text { Direct film } \\
\text { Gram stain }\end{array}$ \\
$\begin{array}{l}\text { Bacterial flora-type } \\
\text { and quantity. Pus cells- } \\
\text { quantity }\end{array}$
\end{tabular} $\begin{aligned} & \begin{array}{l}\text { Presence of } \\
\text { significant } \\
\text { eosinophilia }\end{array} \\
& \begin{array}{l}\text { Giemsa stain } \\
\text { agar } 37^{\circ} \mathrm{C} \text { for } \\
24 \mathrm{~h} \mathrm{in} \mathrm{CO}_{2} \\
\text { incubator }\end{array}\end{aligned}$

on to Sensitest agar.

Add antibiotic discs

and incubate $37^{\circ} \mathrm{C}$ in

$\mathrm{CO}_{\mathrm{z}}$ incubator

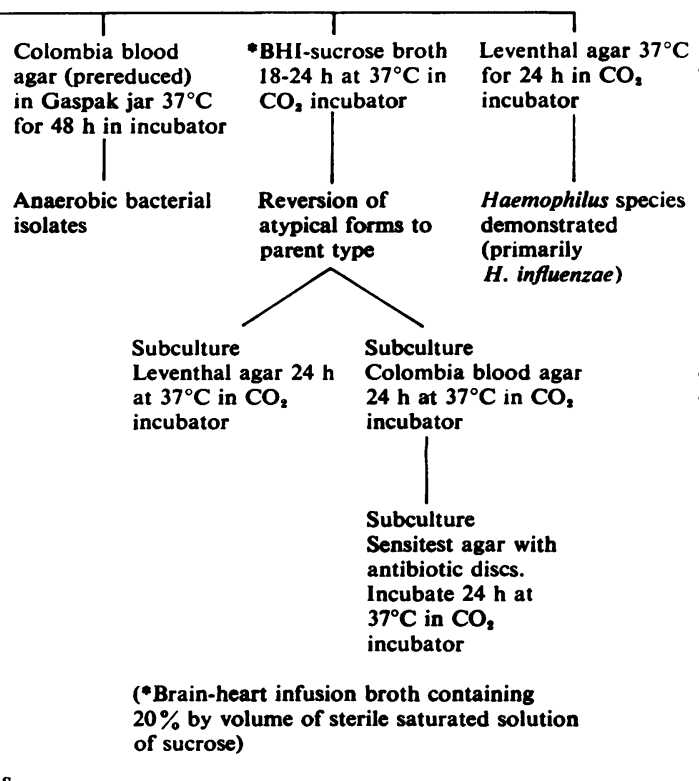

Table 1 Numbers and percentages of organisms isolated from sinus exudates, listed according to methods of collection and species

\begin{tabular}{|c|c|c|c|c|c|}
\hline Species & $\begin{array}{l}\text { Middle meatal } \\
\text { aspirate }\end{array}$ & Antral wash & Antral pus & Total & Percentage \\
\hline Strep. pneumoniae & 43 & 6 & 4 & 53 & $27 \cdot 6$ \\
\hline Staph. aureus & 29 & 10 & 4 & 43 & $22 \cdot 4$ \\
\hline H. influenzae & 15 & 6 & 1 & 22 & 11.5 \\
\hline Klebsiella spp. & 13 & 5 & 2 & 20 & $10 \cdot 4$ \\
\hline$\beta$-haemolytic strep A & 9 & 4 & - & 13 & $6 \cdot 8$ \\
\hline Peptostreptococcus spp. & 6 & 1 & 3 & 10 & $5 \cdot 2$ \\
\hline Pseudomonas spp. & 5 & 3 & 1 & 9 & $4 \cdot 7$ \\
\hline Non-haemolytic strep & 3 & 2 & - & 5 & $2 \cdot 6$ \\
\hline Commensal flora & 4 & - & - & 4 & $2 \cdot 1$ \\
\hline Bacteroides spp. & 2 & 1 & - & 3 & 1.6 \\
\hline Serratia spp. & 2 & - & 1 & 3 & 1.6 \\
\hline H. parainfluenzae & 2 & - & - & 2 & 1.0 \\
\hline Candida albicans & 2 & - & - & 2 & $1 \cdot 0$ \\
\hline Proteus morgani & 1 & - & - & 1 & 0.5 \\
\hline Micrococcus spp. & - & 1 & - & 1 & 0.5 \\
\hline Totals & 136 & 39 & 17 & 192 & $100 \cdot 0$ \\
\hline No growths & 13 & 4 & 2 & 19 & $9 \cdot 5$ \\
\hline
\end{tabular}

half of these (see Discussion). The 19 sterile cultures were included in this 'no organism' group with one exception-that in a patient found to have been on non-admitted, self-administered antibiotic therapy.

The Giemsa-stained films of exudate produced no significant eosinophilias, suggesting an absence of any allergic element in the patients examined. No fungal structures were demonstrated in any stained film.

QUALITY OF SPECIMENS

All specimens were graded for the amount of pus present. The ratios were: scanty pus, 62 specimens $(31 \%)$; moderate pus, 88 specimens $(44 \%)$; heavy 
Table 2 Atypical bacterial forms isolated from hypertonic broth cultures: species, numbers, percentages, and sources of exudates

\begin{tabular}{|c|c|c|c|c|c|}
\hline Species & $\begin{array}{l}\text { Middle meatal } \\
\text { aspirate }\end{array}$ & Antral wash & Antral pus & Total & Percentage \\
\hline $\begin{array}{l}\text { Staph. aureus } \\
\text { Klebsiella spp. } \\
\text { Strep. pneumoniae } \\
\text { Pseudomonas spp. } \\
\text { H. influenzae } \\
\text { B-haemolytic. strep A } \\
\text { H. parainfluenzae } \\
\text { Serratia spp. }\end{array}$ & $\begin{array}{r}22 \\
10 \\
4 \\
3 \\
3 \\
2 \\
2 \\
1\end{array}$ & $\begin{array}{l}3 \\
2 \\
1 \\
1 \\
1 \\
2 \\
1\end{array}$ & $\begin{array}{l}3 \\
2 \\
-1 \\
- \\
-\end{array}$ & $\begin{array}{r}28 \\
14 \\
5 \\
5 \\
4 \\
4 \\
2 \\
2\end{array}$ & $\begin{array}{r}43 \cdot 9 \\
21 \cdot 9 \\
7 \cdot 8 \\
7 \cdot 8 \\
6 \cdot 2 \\
6 \cdot 2 \\
3 \cdot 1 \\
3 \cdot 1\end{array}$ \\
\hline Totals & 47 & 11 & 6 & 64 & $100 \cdot 0$ \\
\hline
\end{tabular}

Table 3 Sex and age classification of patients

\begin{tabular}{lllllllllr}
\hline Sex & Age $(y r)$ & $11-20$ & $21-30$ & $31-40$ & $41-50$ & $51-60$ & $61-70$ & $71-80$ & Total \\
\cline { 2 - 9 } & 10 & $11-21$ & 15 & 10 & 11 & 2 & 1 & 83 \\
\hline Male & 8 & 15 & 30 & 38 & 15 & 6 & 4 & 2 & 117 \\
Female & 6 & 16 & &
\end{tabular}

pus, 50 specimens $(25 \%)$. It was significant that 13 sterile cultures, or $80 \%$ of all sterile cultures, derived from exudates containing only scanty pus.

\section{SEASONAL CHANGES}

Since sampling was spread evenly throughout the year, any seasonal change in the bacterial flora should have been apparent; no such changes were noted.

\section{Discussion}

The predominance of Streptococcus pneumoniae in this series is in agreement with the findings of several previously published surveys (Lystad et al., 1964; Sparrevohn and Buch, 1946; Urdal and Berdal, 1949; Björkwall, 1950; Montgomery Smith and Smith, 1971). The importance of the second highest isolate is not so clear. The literature reviewed shows a sharp division of opinion regarding Staphylococcus aureus as a cause of sinusitis. Some authors doubt its pathogenic status (Lystad et al., 1964; Kinnman et al., 1967; Dawes, 1971; Chapnik and Bach, 1976) while others acknowledge its place in the disease (Sparrevohn and Buch, 1946; Reynolds et al., 1964; Rulon, 1970; Montgomery Smith and Smith, 1971; Frederick and Braude, 1974).

This paper presumes pathogenicity for the following reasons:

(1) Staph. aureus was the sole isolate in 43 cases of acute sinusitis and its incidence was proportionately equal by all three collection methods.
(2) Where the organism was grown on standard media, characteristic Gram-positive cocci were almost invariably present, as the sole organism, in the exudates.

(3) Where hypertonic broth was required for reversion of atypical strains to parent form (66\% of all Staph. aureus isolates), approximately half the stained films of exudate showed scanty Gram-variable cocci, many with distortion effects. A further $30 \%$ showed pleomorphic, Gramnegative bodies of variable size, and the remainder showed no obvious structures. The absence of presumptive cell wall-deficient organisms, however, does not appear to exclude their presence (Cate, 1974) within the debris of stained films.

It must also be conceded that a commensal role for this organism does not exclude the possibility of a pathogenic role for the same organism in the sinuses, particularly in chronic sinusitis under successive antibiotic treatments. The antibiotic sensitivity patterns of this species sustains this contention in that only five of the 43 isolates were fully sensitive to the five drugs of common choice; 14 strains were resistant to two antibiotics; 12 strains were resistant to three antibiotics; 10 strains were resistant to four antibiotics; and two strains were resistant to all five antibiotics. Only one strain was methicillin-resistant.

Species in general did not appear to be age-related although, in subjects under the age of 10 years, Strep. pneumoniae and $H$. influenzae accounted for $68 \%$ of isolates, which is in general agreement with 
published surveys (Rulon, 1970; Montgomery Smith and Smith, 1971; Chapnik and Bach, 1976).

Some investigators have demonstrated large numbers of anaerobes in sinus exudates (Fredette et al., 1961; Frederick and Braude, 1974; Kidder et al., 1975). With only 13 isolates, this series has produced a disappointingly low percentage $(6 \cdot 8 \%)$. This may be due to the fact that cultures were incubated for a maximum of 48 hours, a time limitation imposed for clinical reasons. Further work is proceeding in this area and is hoped to be a subject for later publication.

Strains of organisms damaged by prior antibiotic treatment present problems of laboratory isolation in most pyogenic infections, including sinusitis (Barile et al., 1963; Godzeski et al., 1965; Guze. 1968; Gnarpe and Lundberg, 1971; Bhattacharyya et al., 1972; Sprinkle, 1972). The organisms in this series isolated only from hypertonic broth pose a problem of nomenclature. Although their demonstration required incubation in hypertonic broth, they did not meet the commonly accepted criteria for L-forms, spheroplasts, or protoplasts (Guze, 1968; Feingold, 1969) either in extended serial subculturing requirements or in colonial appearances once reversion to the parent form had been achieved. It is suggested that these isolates are 'atypical bacterial forms', as defined by Charache (1968), and because of their swift reversion to parent form are a presumptive pathogen in this site. This contention is supported by a significant number of clinical remissions in affected patients, obtained by antibiotic treatment (other than those of the penicillin group) directed solely against these organisms. Atypical bacterial forms may reasonably be construed as organisms with defective cell walls within this context. In this series, 64 out of 192 isolates $(33 \%)$ were demonstrated only by hypertonic broth culture, and material from all three collection methods was included. The broad range of species suggests that such media are essential better to define the bacteriology of sinus exudates.

The 19 sterile exudates were all associated with very recent antibiotic therapy. No more than two organisms were found in any mixed infection and no particular pairing was noted although four out of 11 had an anaerobe as a member, two each of Bacteroides and Peptostreptococcus species.

Commensal flora is generally considered to comprise Neisseria catarrhalis, Streptococcus viridans, diphtheroids, and Staphylococcus epidermidis in the upper respiratory tract. One of the more encouraging features of the described regime is the very low number of commensal-contaminated specimens $(2 \%)$.
The following conclusions, therefore, seem to be $\frac{\text { 을 }}{\text { alid: }}$
1) Since there is very little difference between the (1) Since there is very little difference between the
findings from the three types of specimen collection, middle meatal aspiration offers a safe을 and useful technique applicable to all age groups. $\frac{\bar{\rho}}{\bar{\sigma}}$

(2) The suspicion that middle meatal specimens $\mathbb{\Omega}_{\mathscr{Q}}$ routinely risk contamination by commensal flora is not supported by this series.

(3) The satisfactory isolation of presumptive pathogens from sinus exudates is dependent on a $\overrightarrow{\vec{\omega}}$ combination of standard media and hypertonic $\stackrel{\mathscr{S}}{\circ}$ broth culture.

(4) This regime, as a whole, is simple to operate, $\dot{\omega}$ relatively inexpensive, time-conserving, and fits ${ }_{\omega}^{\omega}$ easily into the routine of the clinical laboratory. N

I am grateful to Miss Anne Grigor for technicalo assistance and to those practitioners who allowedme access to their patients for the purposes of this? survey.

\section{References}

Agbim, O. G. (1975). A comparative trial of doxycycline and ampicillin in the treatment of acute sinusitis. Chemotherapy, 21, Supplement 1, 68-75.

Axelsson, A., and Brorson, J. E. (1973). The correlation between bacteriological findings in the nose and $\underset{\Omega}{\mathbb{Q}}$ maxillary sinus in acute maxillary sinusitis. Laryngo $-\overrightarrow{\vec{O}}$ scope, 83, 2003-2011.

Barile, M. F., Graykewski, E. A., Driscoll, E. J., and Riggs, D. B. (1963). L form of bacteria isolated from recurrent aphthous stomatitis lesions. Oral Surgery, 16, 1395-1402.

Bhattacharyya, T. K., Mehra, Y. N., and Agarwal, S. C. (1972). Incidence of bacteria, L-form and mycoplasma 3 in chronic sinusitis. Acta Otolaryngologica, 74, 293-296. Björkwall, T. (1950). Bacteriological examinations in maxillary sinusitis. Acta Otolaryngologica, Supplement 83, 9-58.

Cate, T. R. (1974). Cell wall-defective bacteria. In: إ Manual of Clinical Microbiology, edited by E. H.ㅡㅡㅁ Lennette, E. H. Spaulding and J. P. Truant, 2nd edition, pp. 338-343. American Society for Micro- $-\infty$ biology, Washington D. C.

Chapnik, J. S., and Bach, M. C. (1976). Bacterial and fungal infections of the maxillary sinus. Otolaryngo- $\omega$ logic Clinics of North America, 9, 43-54.

Charache, P. (1968). Atypical bacterial forms in humane disease. In: Microbial Protoplasts, Spheroplasts and $\overparen{\Phi}$ L-Forms, pp. 484-494. Williams \& Wilkins, Baltimore. Cowan, S. T., and Steel, K. J. (1974). Manual for the 0 Identification of Medical Bacteria, 2nd edition. Cambridge University Press, Cambridge.

Dawes, J. D. K. (1971). Chemotherapy in infections of the ear, nose and throat. Practitioner, 207, 735-742.

Eneroth, C. M., Lundberg, C., and Wretlind, B. (1975) Antibiotic concentrations in maxillary sinus secretionso 
and in the sinus mucosa. Chemotherapy, 21, Supplement 1, 1-7.

Feingold, D. S. (1969). Biology and pathogenicity of microbial spheroplasts and L-forms. New England Journal of Medicine, 281, 1159-1170.

Frederick, J., and Braude, A. I. (1974). Anaerobic infection of the paranasal sinuses. New England Journal of Medicine, 290, 135-137.

Fredette, V., Auger, A., and Forget, A. (1961). Anaerobic flora of chronic nasal sinusitis in adults. Canadian Medical Association Journal, 84, 164-165.

Gnarpe, H., and Lundberg, C. (1971). L-phase organisms in maxillary sinus secretions. Scandinavian Journal of Infectious Diseases, 3, 257-259.

Godzeski, C. W., Brier, G., Griffith, R. S., and Black, H. R. (1965). Association of bacterial L-phase organisms in chronic infections (Letter). Nature, 205, 1340.

Guze, L. B. ed. (1968). Microbial protoplasts, spheroplasts and L-forms. Williams and Wilkins, Baltimore.

Kidder, T. M., Toohill, R. J., Unger, J. D., and Lehman, R. H. (1975). Ethmoid sinus surgery. In The Year Book of the Ear, Nose \& Throat, edited by M. S. Strong and M. M. Paparella, pp. 171-172. Year Book Medical Publishers, Chicago.

Kinnman, J., Lee, C. W., and Park, S. H. (1967). Bacterial flora in chronic, purulent maxillary sinusitis. Acta Otolaryngologica, 64, 37-44.

Lancet (1974). Chronic sinusitis. Editorial. Lancet, 1, 442.

Lundberg, C., Gullers, K., and Malmborg, A-S. (1968). Antibiotics in sinus secretions (Letter). Lancet, 2, 107-108.

Lystad, A., Berdal, P., and Lund-Iversen, L. (1964). The bacterial flora of sinusitis with an in-vitro study of the bacterial resistance to antibiotics. Acta Otolaryngologica, Supplement 188, 390-399.

Montgomery Smith, J., and Smith, I. M. (1971). The medical treatment of sinusitis. Otolaryngologic Clinics of North America, 4, 39-55.

Nelson, J. D. (1974). Should ampicillin be abandoned for treatment of Haemophilus influenzae disease? (Editorial). Journal of the American Medical Association, 229, 322-324.

Palva, T., Grönrees, J. A., and Palva, A. (1962). Bacteriology and pathology of chronic maxillary sinusitis. Acta Otolaryngologica, 54, 159-175.

Reynolds, R. C., Catlin, F. I., and Cluff, L. E. (1964). Bacteriology and antibiotic treatment of acute maxillary sinusitis. Bulletin of the Johns Hopkins Hospital, 114, 269-278.

Rulon, J. T. (1970). Sinusitis in children. Postgraduate Medicine, 48 (2), 107-112.

Sparrevohn, U. R., and Buch, A. (1946). The bacteriology of maxillary sinusitis. Acta Otolaryngologica, 34, 425-436.

Sprinkle, P. M. (1972). Current status of Mycoplasmatales and bacterial variants in chronic otolaryngic disease. Laryngoscope, 132, 737-747.

Urdal, K., and Berdal, P. (1949). The microbial flora in 81 cases of maxillary sinusitis. Acta Otolaryngologica, 37, 20-25.

Requests for reprints to: R C Bridger, Pathology Laboratory, Colston House, 137 Kilmore Street, Christchurch 1, New Zealand. 